\title{
Pentoxifylline added to freezing or post-thaw extenders does not improve the survival or in vitro fertilising capacity of boar spermatozoa
}

\author{
María A Gil, Marta Hernandez, Jordi Roca, Carmen Almiñana, Xiomara Lucas, Cristina Cuello, \\ Juan M Vazquez and Emilio A Martínez
}

Department of Medicine and Animal Surgery, Faculty of Veterinary Medicine, University of Murcia, Campus de Espinardo, E-30100 Murcia, Spain

Correspondence should be addressed to M A Gil; Email: mariagil@um.es

\begin{abstract}
This study evaluated whether pentoxifylline added to freezing and thawing extenders influenced the function of boar spermatozoa. In Experiment 1, pooled ejaculated sperm-rich fractions were frozen in $0.5 \mathrm{ml}$ straws after dilution in extender supplemented with pentoxifylline to a final concentration of $0,2,4,8,16$ or $32 \mathrm{mM}$. The addition of 4, 8, 16 and $32 \mathrm{mM}$ pentoxifylline to the freezing extender significantly decreased the progressive and total motility of spermatozoa. The percentage of viable spermatozoa with intact acrosomes as well as the penetration rate and the efficiency of fertilisation were significantly lower in pentoxifylline-treated groups compared with the untreated control. In Experiment 2, a pool of three straws with 'good' post-thaw sperm quality parameters and another three straws with 'poor' sperm quality were diluted in extender with 0, 1, 2, 4, 8, 16 or 32 mM pentoxifylline. Post-thaw samples with both 'good' and 'poor' sperm quality with $0,2,4,8$ and $16 \mathrm{mM}$ were used to assess IVF parameters. The addition of pentoxifylline to post-thaw extender did not improve the post-thaw motility or viability of spermatozoa compared with the control. The in vitro penetration was higher $(P<0.05)$ than the control for oocytes fertilised with spermatozoa that were thawed and incubated in extender with 4, 8 and $16 \mathrm{mM}$ pentoxifylline. However, no differences were observed in the efficiency of fertilisation. We conclude that pentoxifylline, as a supplement added to the freezing extender, has a deleterious effect and that it does not improve the survival or in vitro fertilising efficiency of frozen-thawed boar spermatozoa when added after thawing.

Reproduction (2010) 139 557-564
\end{abstract}

\section{Introduction}

Fertility is generally low after artificial insemination with frozen-thawed boar spermatozoa, as compared to that obtained with fresh semen (Johnson et al. 2000, Roca et al. 2005a, Grossfeld et al. 2008). A primary reason for this low fertility is a reduction in the motility, viability and fertilising potential of the spermatozoa after the freeze-thaw process. Freezing and thawing cause damage to the acrosome and plasma membranes of boar spermatozoa (Maxwell \& Johnson 1999, Eriksson et al. 2001). This damage is exacerbated during the cryopreservation process by a decrease in the lipid content of the membranes that contain a high proportion of polyunsaturated fatty acids. The decrease in lipid content indicates lipid peroxidation in the presence of reactive oxygen species (Cerolini et al. 2001).

Many substances have been tested to determine whether they enhance the resistance of spermatozoa to the stress of freezing and thawing in several species, including the pig (Roca et al. 2004, 2005b,
Breininger et al. 2005, Bathgate et al. 2006, Corcuera et al. 2007, De Mercado et al. 2009, Hu et al. 2009). Pentoxifylline, a methylxanthine derivate, is an inhibitor of phosphodiesterase. This substance has also been used to stimulate the motility of fresh and/or frozen-thawed human (Hammitt et al. 1989, Brennan \& Holden 1995, Nassar et al. 1999, Huang et al. 2003), equine (Gradil \& Ball 2000, Marques et al. 2002), bovine (Numabe et al. 2001), ovine (Maxwell et al. 1995), feline (Stachecki et al. 1995) and canine spermatozoa (Koutsarova et al. 1997). Also, we have observed that pentoxifylline is able to stimulate the motility of fresh boar spermatozoa (MA Gil, J Roca, JM Vasquez \& EA Martinez, unpublished data; shown in Fig. 1). Pentoxifylline inhibits CAMP phosphodiesterase, thus increasing the intracellular cAMP concentration (Garbers et al. 1971). $A$ rise in CAMP concentration causes an increase in the cAMP-dependent processes of spermatozoa such as motility, capacitation and acrosome reaction in spermatozoa (Armstrong et al. 1994, Aitken 1997). 


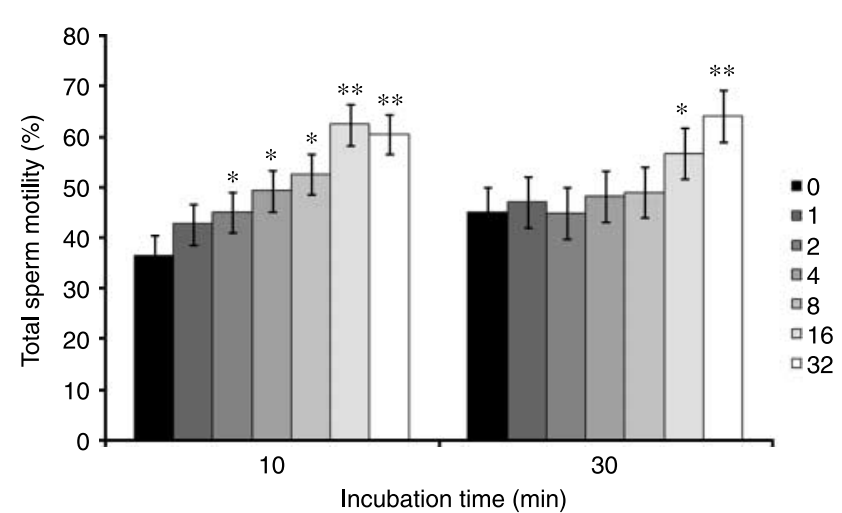

Figure 1 Percentage (least-square means \pm s.E.M.) of total motility of fresh boar semen incubated for 10 and $30 \mathrm{~min}$ in the absence (control, 0 ; black bars) or presence of varying concentrations of pentoxifylline $(1,2,4,8,16$ and $32 \mathrm{mM})$. Differences from the control $(0 \mathrm{mM})$ are indicated by asterisks $(* P<0.05 ; * * P<0.01)$.

In addition, pentoxifylline has been proposed too as a cryoprotectant of human spermatozoa due to its protection of spermatozoa membranes from freezing damage, allowing for better post-thaw motility (Bell et al. 1993) and viability (Wang et al. 1993, Esteves et al. 1998). Moreover, it has a protective effect on sperm membranes as it scavenges reactive oxygen radicals and then reduces lipid peroxidation (Yovich et al. 1994, McKinney et al. 1996, Okada et al. 1997). In spite of these promising benefits, pentoxifylline has not been evaluated as an additive for boar spermatozoa undergoing freezing and thawing. Therefore, the aim of this study was to evaluate whether pentoxifylline, added to the freezing and thawing extenders, influences the survival and function of frozen-thawed boar spermatozoa.

\section{Results}

\section{Experiment 1: effect of pentoxifylline added to the freezing extender on the post-thaw quality and IVF rate of spermatozoa}

The data on post-thaw motility and viability of boar spermatozoa are summarised in Table 1. Pentoxifylline decreased the percentages of motile spermatozoa and progressive motile spermatozoa at concentrations of $4,8,16$ and $32 \mathrm{mM}(P<0.05)$, as compared with the control group (0 pentoxifylline). The percentage of viable spermatozoa with intact acrosomes was significantly lower $(P<0.05)$ in the pentoxifylline-treated groups, as compared with the control, particularly in the $32 \mathrm{mM}$ pentoxifylline group. Moreover, the number of viable acrosome-reacted spermatozoa was three times higher $(P<0.05)$ in the $32 \mathrm{mM}$ pentoxifylline group than in the control.

The data from IVF (Table 2 ) clearly showed that pentoxifylline in the freezing extender reduced $(P<0.05)$ the fertilisation rate and the efficiency of fertilisation, as compared with the control group. Pentoxifylline had no effect on the monospermic fertilisation rate.

\section{Experiment 2: effect of pentoxifylline added to the post-thaw extender on the survival and IVF rate of spermatozoa}

Pentoxifylline, added to the post-thaw extender, did not improve the post-thaw motility or viability of spermatozoa independently of sperm freezability (good versus poor freezers) and incubation times (30, 150 and $300 \mathrm{~min}$ ). Moreover, $32 \mathrm{mM}$ pentoxifylline significantly $(P<0.05)$ decreased the total motility of spermatozoa, as compared with the other groups.

There were not any interactions between pentoxifylline concentration, post-thaw evaluation times and 'good' and 'poor' post-thaw sperm quality for any of the parameters evaluated. Therefore, the data are presented as means pooled (Table 3).

The addition of 16 and $32 \mathrm{mM}$ pentoxifylline increased $(P<0.05)$ the number of viable acrosome-reacted spermatozoa twofold and threefold respectively.

In relation to IVF parameters, only the fertilisation rate was influenced by the presence of pentoxifylline in the post-thaw extender independently of sperm freezability (good versus poor freezers; Table 4). Fertilisation was higher $(P<0.05)$ for oocytes fertilised with spermatozoa thawed and incubated in extender supplemented with 4,8 and $16 \mathrm{mM}$ pentoxifylline. However, no differences were observed in monospermy or in the efficiency of fertilisation. There were no interactions

Table 1 Effect of pentoxifylline (PTX) added to the freezing extender on the post-thaw motility and viability of boar spermatozoa. Data (least-square means \pm S.E.M.) are from six replicates.

\begin{tabular}{lccccc}
\hline & \multicolumn{2}{c}{ Motility parameters } & & \multicolumn{2}{c}{ Viability parameters } \\
\cline { 2 - 3 } \cline { 5 - 6 } Treatment PTX $(\mathrm{mM})$ & Total motile $(\%)$ & Rapid progressive $(\%)$ & & Acrosome intact $(\%)$ & Acrosome reacted $(\%)$ \\
\hline 0 & $49.7 \pm 4.2^{*}$ & $13.2 \pm 1.2^{*}$ & & $54.0 \pm 4.6^{*}$ & $0.7 \pm 0.4^{*}$ \\
2 & $38.9 \pm 4.2^{*,+}$ & $9.5 \pm 1.2^{*}$ & & $31.1 \pm 4.6^{+}$ & $0.7 \pm 0.4^{*}$ \\
4 & $26.6 \pm 4.2^{+, \neq}$ & $4.5 \pm 1.2^{+}$ & & $20.7 \pm 4.6^{+, \neq}$ & $0.7 \pm 0.4^{*}$ \\
8 & $24.5 \pm 4.2^{+, \neq}$ & $4.5 \pm 1.2^{+}$ & & $16.7 \pm 4.6^{+, \neq}$ & $0.4 \pm 0.4^{*}$ \\
16 & $20.5 \pm 4.2^{\ddagger}$ & $2.8 \pm 1.2^{+}$ & & $11.6 \pm 4.6^{\ddagger}$ & $1.4 \pm 0.4^{*,+}$ \\
32 & $11.4 \pm 4.2^{*}$ & $0.6 \pm 1.2^{+}$ & & $6.2 \pm 4.6^{\ddagger}$ & $2.7 \pm 0.4^{+}$ \\
\hline
\end{tabular}

\footnotetext{
${ }^{*,+, \neq}$ Within the same column indicates statistical differences $P<0.05$.
} 
Table 2 Effect of pentoxifylline (PTX) added to the freezing extender on IVF parameters. Data (least-square means \pm s.E.M.) are from three replicates.

\begin{tabular}{lcccc}
\hline Treatment PTX $(\mathrm{mM})$ & Total examined $\left(\mathrm{N}^{\circ}\right)$ & Fertilised oocytes & Monospermic oocytes & Efficiency of fertilisation \\
\hline 0 & 181 & $51.4 \pm 2.7^{*}$ & $89.8 \pm 4.1$ & $34.8 \pm 2.6^{*}$ \\
2 & 171 & $17.5 \pm 2.8^{+}$ & $83.2 \pm 6.0$ & $14.6 \pm 2.7^{+}$ \\
4 & 177 & $15.8 \pm 2.8^{+, \neq}$ & $92.5 \pm 6.2$ & $14.7 \pm 2.6^{+}$ \\
8 & 174 & $17.8 \pm 2.8^{+}$ & $86.6 \pm 5.9$ & $7.5 \pm 2.6^{+}$ \\
16 & 178 & $9.6 \pm 2.8^{+, \neq}$ & $82.0 \pm 7.9$ & $7.9 \pm 2.7^{+}$ \\
32 & 186 & $4.8 \pm 2.7^{\ddagger}$ & $99.5 \pm 10.7$ & $4.8 \pm 2.6^{+}$ \\
\hline
\end{tabular}

The value for monospermic oocytes represents the percentage of the number of monospermic oocytes/total of fertilised oocytes; the efficiency of fertilisation was calculated as the percentage of the number of monospermic oocytes/total number of inseminated oocytes. ${ }^{*,+, \neq}$ Within the same column indicates statistical differences $P<0.05$.

between pentoxifylline concentration, post-thaw evaluation time (30 and $150 \mathrm{~min}$ ) and 'good' and 'poor' postthaw sperm quality for any of the parameters evaluated. Therefore, the data are presented as means pooled.

\section{Discussion}

Pentoxifylline is one of the most effective additives for improving the motility and acrosome reactivity of human spermatozoa. It has been also used to enhance the motility of fresh and frozen spermatozoa from a number of domestic animals (Maxwell et al. 1995, Stachecki et al. 1995, Koutsarova et al. 1997, Gradil \& Ball 2000, Numabe et al. 2001, Huang et al. 2003). However, to the best of our knowledge, this is the first report on the effect of pentoxifylline on the quality of frozen-thawed boar spermatozoa and their ability to fertilise in vitro-matured porcine oocytes.

Pentoxifylline is thought to act as a cryoprotectant of spermatozoa (Bell et al. 1993, Wang et al. 1993, Esteves et al. 1998), and thus, the first experiment of this study explored the potential effect of pentoxifylline added to the spermatozoa before freezing. Under the present experimental conditions, 4, 8, 16 and $32 \mathrm{mM}$ pentoxifylline added to the freezing extender decreased the postthaw motility and the viability of spermatozoa. This deleterious effect has also been observed in ovine (Maxwell et al. 1995) and equine (Gradil \& Ball 2000) species. Moreover, a detrimental effect of pentoxifylline on human spermatozoa was also observed at a concentration of $10 \mathrm{mM}$ (Tournaye et al. 1994) suggesting a concentration-dependent toxic effect when the substance is added to semen before freezing. It should be noted that the range of pentoxifylline concentrations used in the present study was based on those used in previous reports (Maxwell et al. 1995, Numabe et al. 2001, Glogowski et al. 2002). Maxwell et al. (1995) indicated that the negative effects of pentoxifylline added prior to freezing could be the result of a longer exposure of the spermatozoa to this compound at the time of freezing and thawing. It appears as though elevated CAMP concentrations promote disruption of the activity of CAMP-associated ion channels in the plasma membrane. This disruption during freezing and thawing may alter the movement of ions and water across the sperm membrane and increase membrane damage. In our study, the spermatozoa were diluted with extender supplemented with pentoxifylline before packing into the 0.5 PVC straws (Minitüb, Germany) and freezing by using a controlled-rate freezer from 5 to $-80{ }^{\circ} \mathrm{C}$ at $40{ }^{\circ} \mathrm{C} / \mathrm{min}$. It means that the spermatozoa were incubated with pentoxifylline for only $10 \mathrm{~min}$, compared with the incubation time of 90-120 min used with ram spermatozoa by Maxwell et al. (1995). However, this short incubation time could be long enough to increase the membrane damage caused by cryopreservation. Therefore, we suggest that the duration of exposure of the spermatozoa to the pentoxifylline may have been responsible for the low post-thaw sperm survival observed in the present study.

It is well known that only motile and membrane intact spermatozoa are able to undergo the acrosome reaction,

Table 3 Effect of pentoxifylline (PTX) added to the post-thaw extender on the post-thaw motility and viability of boar spermatozoa. Data (least-square means \pm S.E.M.) are from nine replicates.

\begin{tabular}{|c|c|c|c|c|}
\hline \multirow{2}{*}{ Treatment PTX (mM) } & \multicolumn{2}{|c|}{ Motility parameters } & \multicolumn{2}{|c|}{ Viability parameters } \\
\hline & Total motile (\%) & Rapid progressive (\%) & Acrosome intact $(\%)$ & Acrosome reacted $(\%)$ \\
\hline 0 & $42.3 \pm 3.6^{*}$ & $11.6 \pm 2.2$ & $47.5 \pm 2.8$ & $0.9 \pm 0.3^{*}$ \\
\hline 1 & $42.3 \pm 3.6^{*}$ & $12.2 \pm 2.2$ & $43.0 \pm 2.8$ & $1.0 \pm 0.3^{*,+}$ \\
\hline 2 & $43.7 \pm 3.6^{*}$ & $12.0 \pm 2.2$ & $43.8 \pm 2.8$ & $1.1 \pm 0.3^{*,+}$ \\
\hline 4 & $43.5 \pm 3.6^{*}$ & $13.5 \pm 2.2$ & $44.0 \pm 2.8$ & $1.2 \pm 0.3^{*}{ }^{+}$ \\
\hline 8 & $44.7 \pm 3.6^{*}$ & $13.1 \pm 2.2$ & $45.2 \pm 2.8$ & $1.1 \pm 0.3^{*,+}$ \\
\hline 16 & $38.6 \pm 3.6^{*,+}$ & $9.61 \pm 2.2$ & $43.9 \pm 2.8$ & $2.0 \pm 0.3^{+}$ \\
\hline 32 & $29.0 \pm 3.6^{\dagger}$ & $7.8 \pm 2.2$ & $40.5 \pm 2.8$ & $3.2 \pm 0.3^{\ddagger}$ \\
\hline
\end{tabular}

\footnotetext{
${ }^{*}, t, \neq$ Within the same column indicates statistical differences $P<0.05$.
} 
Table 4 Effect of pentoxifylline (PTX) added to the post-thaw extender on IVF parameters. Data (least-square means \pm s.E.M.) are from four replicates.

\begin{tabular}{lcccc}
\hline $\begin{array}{c}\text { Treatment } \\
\text { PTX }(\mathrm{mM})\end{array}$ & $\begin{array}{c}\text { Total } \\
\text { examined } \\
\left(\mathrm{N}^{\circ}\right)\end{array}$ & $\begin{array}{c}\text { Fertilised } \\
\text { oocytes }\end{array}$ & $\begin{array}{c}\text { Monospermic } \\
\text { oocytes }\end{array}$ & $\begin{array}{c}\text { Efficiency of } \\
\text { fertilisation }\end{array}$ \\
\hline 0 & 403 & $45.7 \pm 3.6^{*}$ & $75.9 \pm 3.5$ & $33.9 \pm 2.6$ \\
2 & 387 & $53.0 \pm 3.6^{*,+}$ & $70.8 \pm 3.3$ & $36.9 \pm 2.7$ \\
4 & 360 & $59.9 \pm 3.7^{+}$ & $69.8 \pm 3.2$ & $41.2 \pm 2.7$ \\
8 & 367 & $58.3 \pm 3.6^{+}$ & $65.3 \pm 3.2$ & $37.4 \pm 2.7$ \\
16 & 381 & $56.7 \pm 3.6^{+}$ & $69.2 \pm 3.2$ & $38.8 \pm 2.7$ \\
\hline
\end{tabular}

The value for monospermic oocytes represents the percentage of the number of monospermic oocytes/total of fertilised oocytes; the efficiency of fertilisation was calculated as the percentage of the number of monospermic oocytes/total number of inseminated oocytes.

${ }^{*},+$ Within the same column indicates statistical differences $P<0.05$.

penetrate the zona pellucida and fuse with the oocyte (Yanagimachi 1988). Therefore, the lower number of motile and/or membrane intact spermatozoa present in samples frozen with pentoxifylline could be responsible for the decreased in vitro fertilising capacity of frozenthawed spermatozoa.

The effect of pentoxifylline added to semen after thawing was examined in the second experiment. Many authors have demonstrated a positive influence of pentoxifylline on cryopreserved spermatozoa when the substance is added after thawing (human: Brennan \& Holden 1995, Stanic et al. 2002, Huang et al. 2003; equine: Gradil \& Ball 2000, Marques et al. 2002; bovine: Numabe et al. 2001; ovine: Maxwell et al. 1995; feline: Stachecki et al. 1995; canine: Koutsarova et al. 1997). However, this was not confirmed for boar spermatozoa in the present study. The incubation of thawed spermatozoa in the presence of pentoxifylline did not improve the post-thaw survival, regardless of the concentration (from 1 to $32 \mathrm{mM}$ ). Moreover, the addition of $32 \mathrm{mM}$ pentoxifylline significantly decreased the total motility. Brennan \& Holden (1995) also reported a decrease in the quality of human spermatozoa in the presence of a high concentration $(10 \mathrm{mM})$ of pentoxifylline. The concentrations of pentoxifylline used in the present study were similar to those used for the enhancement of sperm quality in other species. However, in contrast to these studies, we did not find any benefit of pentoxifylline to sperm function.

Pentoxifylline had no effect when added to human normozoospermic samples, but it significantly improved the total motility and progressive motility in oligoasthenozoospermic samples (Yovich et al. 1990, Tesarik et al. 1992, Nassar et al. 1999). Moreover, pentoxifylline appears to be useful for improving the motility of spermatozoa in suboptimal human (Paul et al. 1995) and equine ejaculates (Gradil \& Ball 2000). Therefore, in the present study we investigated the effect of pentoxifylline added to the post-thaw extender on the survival and IVF rate of spermatozoa from ejaculates classified as 'good' or 'poor', according to their freezability characteristics. However, the treatment of spermatozoa with pentoxifylline did not improve post-thaw survival or function, regardless of freezability.

It has been suggested that pentoxifylline can maintain motility of spermatozoa for an extended period of time (Maxwell et al. 1995, Marques et al. 2002), and thus, we also evaluated the samples at 150 and 300 min after thawing to determine if pentoxifylline was able to maintain initial motility parameters over time. In contrast with previous reports, the motility of spermatozoa was not retained by the pentoxifylline treatment in this study.

The results found with boar semen in the present study conflict with reports of other mammalian species. As has been mentioned, the effect of pentoxifylline on frozen-thawed boar spermatozoa is unknown. Some species-specific differences have been suggested in the effects of methylxanthines on phosphodiesterase (Tash 1976). However, these species differences should be considered cautiously since there are no studies comparing enzyme responses to methylxanthines between species. The only report on the effect of pentoxifylline on boar spermatozoa is that of reported by Glogowski et al. (2002). These authors demonstrated that pentoxifylline can inhibit the alkaline phosphatase activity of boar spermatozoa, which has some similarity to phosphodiesterase. Nevertheless, this study did not investigate the effects of this methylxanthine on the quality of boar spermatozoa. Our results suggest that the inhibition of alkaline phosphatase or phosphodiesterase may not cause a beneficial effect of pentoxifylline on boar spermatozoa as it does in other species.

Pentoxifylline, similar to other methylxanthines, may increase the proportion of acrosome-reacted spermatozoa (McLaughlin et al. 1992). However, in the present study, only the highest concentration of pentoxifylline tested increased the frequency of the acrosome reaction when added to the spermatozoa both before freezing and after thawing. This finding confirms the suggestion that the frequency of spontaneous acrosome reactions after pentoxifylline treatment may be concentration-dependent (Esteves et al. 1998).

While the addition of pentoxifylline to the post-thaw extender did not improve sperm motility or viability, a significant improvement of IVF rates was observed in spermatozoa exposed to 4, 8 and $16 \mathrm{mM}$ pentoxifylline. The improvement of fertilisation may be caused by the antioxidant effect of pentoxifylline, as suggested by Gavella et al. (1991). Moreover, Numabe et al. (2001) found an increase in fertilisation, monospermy, cleavage and blastocyst rates after treating bull spermatozoa with pentoxifylline. However, in our system, pentoxifylline treatment failed to increase either the number of monospermic oocytes or the efficiency of fertilisation. Therefore, we may assume that pentoxifylline is an ineffective treatment for improving the efficiency of IVF of frozen-thawed boar spermatozoa. 
Our data demonstrate that pentoxifylline, as a supplement added to the freezing extender, has a deleterious effect and, when added after thawing, does not improve the survival or in vitro fertilising efficiency of boar spermatozoa.

\section{Materials and Methods}

\section{Reagents and culture media}

All chemicals used in this study were purchased from Sigma Aldrich Co. unless otherwise stated.

The basic medium used for sperm dilution was Beltsville thawing solution (BTS) composed of $205 \mathrm{mM}$ D-glucose, 20.39 $\mathrm{mM} \mathrm{NaCl}, 5.4 \mathrm{mM} \mathrm{KCl}, 15.01 \mathrm{mM} \mathrm{NaHCO}$ and $3.35 \mathrm{mM}$ EDTA (Johnson et al. 1988) containing kanamycin sulphate $(50 \mu \mathrm{g} / \mathrm{ml})$. The basic medium used for sperm cryopreservation was lactose-egg yolk (LEY) extender composed of $80 \%(\mathrm{v} / \mathrm{v})$ $310 \mathrm{mM} \beta$-lactose solution, $20 \%(\mathrm{v} / \mathrm{v})$ egg yolk and $100 \mu \mathrm{g} / \mathrm{ml}$ kanamycin sulphate.

The medium used for the collection and washing of oocytecumulus complexes was Dulbecco's PBS (DPBS) medium supplemented with $4 \mathrm{mg} / \mathrm{ml} \mathrm{BSA}$ (fraction $\mathrm{V}$ ), $0.34 \mathrm{mM}$ sodium pyruvate, $5.4 \mathrm{mM}$ D-glucose and $70 \mu \mathrm{g} / \mathrm{ml}$ kanamycin (mDPBS). The oocyte maturation medium was BSA-free North Carolina State University-23 composed of $108.73 \mathrm{mM}$ $\mathrm{NaCl}, 4.78 \mathrm{mM} \mathrm{KCl}, 1.7 \mathrm{mM} \mathrm{CaCl} 2 \cdot 2 \mathrm{H}_{2} \mathrm{O}, 1.19 \mathrm{mM} \mathrm{KH}_{2} \mathrm{PO}_{4}$, $1.19 \mathrm{mM} \mathrm{MgSO} \cdot 7 \mathrm{H}_{2} \mathrm{O}, 25.07 \mathrm{mM} \mathrm{NaHCO}_{3}, 5.55 \mathrm{mM}$ D-glucose, $1 \mathrm{mM}$ L-glutamine, $7 \mathrm{mM}$ taurine, $5 \mathrm{mM}$ hypotaurine, $75 \mu \mathrm{g} / \mathrm{ml}$ potassium penicillin $\mathrm{G}$ and $50 \mu \mathrm{g} / \mathrm{ml}$ streptomycin sulphate (NCSU-23, Petters \& Wells 1993). This medium was supplemented with $10 \%(\mathrm{v} / \mathrm{v})$ porcine follicular fluid, $0.1 \mathrm{mg} / \mathrm{ml}$ cysteine, $10 \mathrm{ng} / \mathrm{ml}$ epidermal growth factor, $10 \mathrm{IU} / \mathrm{ml}$ eCG (Folligon, Intervet International BV, Boxmeer, The Netherlands) and $10 \mathrm{IU} / \mathrm{ml}$ hCG (Veterin Corion, Divasa Farmavic, S A, Barcelona, Spain). The basic medium used for IVF was the same as that was used by Abeydeera \& Day (1997), designated as modified Tris-buffered medium (mTBM), consisting of $113.1 \mathrm{mM} \mathrm{NaCl}, 3 \mathrm{mM} \mathrm{KCl}, 7.5 \mathrm{mM} \mathrm{CaCl} 2 \cdot 2 \mathrm{H}_{2} \mathrm{O}$, $20 \mathrm{mM}$ Tris (Trizma Base, Sigma), $11 \mathrm{mM}$ D-glucose and $5 \mathrm{mM}$ sodium pyruvate, supplemented with $2 \mathrm{mM}$ caffeine and $0.2 \%$ BSA. The embryo culture medium was NCSU-23 with $0.4 \%$ BSA. All the media were buffered with $\mathrm{NaOH}$ and $\mathrm{HCl}$ to $\mathrm{pH}$ 7.3-7.4 at room temperature and had a final appropriate osmolarity (270-295 mOsm).

Stock solutions of pentoxifylline (P1784; $64 \mathrm{mM})$ were prepared in BTS for each day of the experiment.

\section{Cryopreservation of spermatozoa}

Sperm samples were cryopreserved using the straw-freezing procedure described by Westendorf et al. (1975) as modified by Thurston et al. (1999) and Carvajal et al. (2004). Briefly, extended semen $\left(1: 1, \mathrm{v} / \mathrm{v}\right.$ in BTS) was cooled to $17^{\circ} \mathrm{C}$ and held at this temperature for $3 \mathrm{~h}$. After centrifugation at $2400 \mathrm{~g}$ for $3 \mathrm{~min}$, the pellets were diluted in LEY $(\mathrm{pH} 6.2$ and 330 $\pm 5 \mathrm{mOsm} / \mathrm{kg}$ ) to a concentration of $1.5 \times 10^{9} \mathrm{spermatozoa} / \mathrm{ml}$. After further cooling to $5{ }^{\circ} \mathrm{C}$ over $120 \mathrm{~min}$, the extended spermatozoa were re-suspended with LEY-Glycerol-Orvus Es
Paste (LEYGO) extender (92.5\% LEY + 1.5\% Equex STM (Nova Chemical Sales Inc., Scituate, MA, USA) and $6 \%$ glycerol, v/v; $\mathrm{pH} 6.2$ and $1145 \pm 17 \mathrm{mOsm} / \mathrm{kg}$ ) to a final concentration of $1 \times 10^{9} / \mathrm{ml}$. The cooled spermatozoa were packed into 0.5 PVC straws, which were frozen using a controlled-rate freezer (IceCube 1810, Minitüb, Germany) from 5 to $-80^{\circ} \mathrm{C}$ at $40^{\circ} \mathrm{C} / \mathrm{min}$, held for $30 \mathrm{~s}$ at $-80^{\circ} \mathrm{C}$, cooled at $70^{\circ} \mathrm{C} / \mathrm{min}$ to $-150^{\circ} \mathrm{C}$ and, finally, plunged into liquid nitrogen $\left(\mathrm{LN}_{2}\right)$.

\section{Thawing and post-thaw evaluation of spermatozoa}

Frozen straws were thawed in a circulating water bath at $37^{\circ} \mathrm{C}$ for $20 \mathrm{~s}$. The thawed spermatozoa were re-extended at $37^{\circ} \mathrm{C}$ with BTS $(1: 2, v / v)$ and kept in the water bath during the evaluation of their motility and viability (plasma membrane and acrosome integrity).

\section{Assessment of sperm motility}

Sperm motility was objectively evaluated using a computerassisted sperm analysis system (Sperm Class Analyzer, Microptic, Barcelona, Spain). Briefly, thawed spermatozoa were further re-suspended in BTS to a concentration of $30 \times 0^{6}$ spermato$\mathrm{zoa} / \mathrm{ml}$. For each evaluation, a $4 \mu \mathrm{l}$ aliquot of the sperm sample was placed in a pre-warmed $\left(39^{\circ} \mathrm{C}\right)$ Makler counting chamber (Sefi Medical Instruments, Haifa, Israel) at $39^{\circ} \mathrm{C}$, and three fields were analysed, including a minimum of 100 spermatozoa/sample. The proportions of total motile sperm and rapid progressive motile sperm (sperm with a motility of up to $50 \mu \mathrm{m} / \mathrm{s}$ and a straightness of up to $75 \%$ ) were measured.

\section{Assessment of sperm membrane integrity}

The membrane integrity of spermatozoa was evaluated using a triple fluorescence staining procedure. Aliquots $(100 \mu \mathrm{l}$ each or $\sim 3 \times 10^{6}$ cells) were transferred into culture tubes, and dyes were added at a final concentration of $25 \mathrm{nM}$ SYBR-14 $(100 \mathrm{mM}$ stock solution B in DMSO; Component A of LIVE/DEAD Sperm Viability Kit, L-C 7011; Molecular Probes, Europe BV, Leiden, The Netherlands), $1 \mu \mathrm{g} / \mathrm{ml}$ of peanut agglutinin conjugated with phycoerythrin (PE)-PNA solution $(1 \mathrm{mg} / \mathrm{ml}$ stock solution Phycoprobe R-PE-PNA, P44; Biomeda Corp., Foster City, CA, USA) and $12 \mu \mathrm{M}$ propidium iodide (Pl; $1.5 \mathrm{mM}$ in PBS; Component B of Sperm Viability Kit). Samples were mixed and incubated at room temperature in the dark for $10 \mathrm{~min}$. Prior to analysis on the flow cytometer, $400 \mu \mathrm{l}$ PBS were added to each sample, and a remixed flow cytometer analysis was performed using a Coulter Epics XLTM (Coulter Corp., Miami, FL, USA). All dyes were excited by an argon ion $488 \mathrm{~nm}$ laser. SYBR-14 fluorescence (particles containing DNA, living cells) was detected with a $525 \mathrm{~nm}$ band-pass (BP) filter, while the PI signal (used to indicate non-viable cells) was detected by a $620 \mathrm{~nm}$ BP filter, and PE-PNA fluorescence (used to indicate cells with damaged acrosomes) was detected using a $575 \mathrm{~nm}$ BP filter. Acquisition and analysis were carried out using EXPO 2000 (Coulter) Software. Debris was gated out based on scatter properties and double-gated out based on SYBR-14 or PI fluorescence. Subpopulations were divided by quadrants, and the frequency of each subpopulation was 
quantified. Acquisition was stopped after recording 10000 gated events, and event rates were maintained at $\sim 800$ cells $/ \mathrm{s}$. Only the percentages of live spermatozoa with intact acrosomes (membrane intact spermatozoa) and live spermatozoa with reacted acrosomes were included in the results.

\section{In vitro oocyte maturation, fertilisation and embryo culture}

Ovaries were obtained from pre-pubertal gilts at a local slaughterhouse and transported to the laboratory at $35^{\circ} \mathrm{C}$ in $0.9 \% \mathrm{NaCl}$ containing $70 \mu \mathrm{g} / \mathrm{ml}$ kanamycin. Oocytes were aspirated from medium-sized follicles (3-6 $\mathrm{mm}$ in diameter) with an 18-gauge needle fixed to a $10 \mathrm{ml}$ disposable syringe. Only oocytes surrounded by a compact cumulus mass that had an evenly granulated cytoplasm were harvested and washed three times in a maturation medium. One hundred oocytes were transferred into each well of a Nunc 4-well multidish containing $500 \mu \mathrm{l}$ of pre-equilibrated maturation medium previously covered with warm mineral oil. The oocytes were cultured at $39{ }^{\circ} \mathrm{C}$ in air containing $5 \% \mathrm{CO}_{2}$ for $22 \mathrm{~h}$ with added hormones and for a further $22 \mathrm{~h}$ without hormonal additives. Thereafter, cumulus cells were removed with $0.1 \%$ hyaluronidase in a maturation medium, and the denuded oocytes were washed three times and placed in $50 \mu \mathrm{l}$ drops of pre-equilibrated IVF medium covered with warm mineral oil in a $35 \times 10 \mathrm{~mm}$ Petri dish (30 oocytes/drop). The dishes with the oocytes were kept in an incubator for about 30 min until spermatozoa were added for fertilisation.

For IVF, $100 \mu \mathrm{l}$ of thawed spermatozoa from each sample were washed three times by centrifugation at $1900 \mathrm{~g}$ for $3 \mathrm{~min}$ in mDPBS. At the end of the washing procedure, the sperm pellet was re-suspended in the fertilisation medium. After appropriate dilution, $50 \mu \mathrm{l}$ with 60000 spermatozoa, of this sperm suspension, were added to the medium that contained the oocytes. Six hours after insemination, the oocytes were washed and transferred (30 oocytes/well) to a Nunc 4-well multidish containing $500 \mu$ of the embryo culture medium and cultured at $39{ }^{\circ} \mathrm{C}$ in air containing $5 \% \mathrm{CO}_{2}$ for $16 \mathrm{~h}$ to assess fertilisation parameters.

\section{Assessment of fertilisation parameters}

To evaluate fertilisation parameters, presumptive zygotes were mounted onto slides, fixed for $48-72 \mathrm{~h}$ in $25 \%(\mathrm{v} / \mathrm{v})$ acetic acid in ethanol at room temperature, stained with $1 \%$ lacmoid in $45 \%(\mathrm{v} / \mathrm{v})$ acetic acid and examined under a phase contrast microscope at $400 \times$ magnification. Oocytes were considered to have been fertilised when they had one or more swollen sperm heads and/or when male pronuclei and their corresponding sperm tails were observed in the ooplasm along with two polar bodies. The fertilisation parameters evaluated were fertilisation (percentage of the number of oocytes fertilised/total mature inseminated), monospermy (percentage of the number of oocytes containing only one male pronucleus/total fertilised) and efficiency of fertilisation (percentage of the number of monospermic oocytes/total inseminated). Degenerated oocytes or oocytes with a broken oolemma or an ooplasm with an abnormal appearance were not counted.

\section{Experimental design}

Two separate experiments were performed to evaluate the effect of the presence of pentoxifylline on boar sperm undergoing freezing and thawing. The range of pentoxifylline concentrations tested (from 1 to $32 \mathrm{mM}$ ) includes those that had been previously used with bovine (Numabe et al. 2001), ovine (Maxwell et al. 1995), equine (Gradil \& Ball 2000, Marques et al. 2002), human (Brennan \& Holden 1995, Nassar et al. 1999, Huang et al. 2003) and boar (Glogowski et al. 2002) spermatozoa.

Experiment 1: effect of pentoxifylline added to the freezing extender on the post-thaw quality and IVF rate of spermatozoa

Three healthy, mature (2-4 years of age) and fertile hybrid boars housed at a commercial insemination station were used as ejaculate donors. Pooled ejaculated sperm-rich fractions collected from the three boars were frozen in $0.5 \mathrm{ml}$ straws after dilution in LEYGO supplemented with pentoxifylline to a final concentration of 0 (control), 2, 4, 8, 16 or $32 \mathrm{mM}$ and incubated for $10 \mathrm{~min}$. This experiment was repeated six times. To evaluate the post-thaw survival of spermatozoa, a pool of two straws were thawed and analysed $30 \mathrm{~min}$ after thawing. Frozen-thawed sperm samples were used to inseminate a total of 1067 in vitro matured oocytes, in three replicates, in order to evaluate IVF parameters.

Experiment 2: effect of pentoxifylline added to the post-thaw extender on the survival and IVF rate of spermatozoa

Frozen-thawed ejaculates from six healthy, mature and fertile hybrid boars from our cryopreserved sperm bank were used as ejaculate donors in this experiment. Three of them had 'good' post-thaw sperm quality parameters $(\geq 50 \%$ motile and viable spermatozoa post thawing), and the other three had 'poor' postthaw sperm quality $(\leq 35 \%$ motile and viable spermatozoa post thawing). In each replicate, a pool of three straws (one per boar) of 'good' and a pool of three straws (one per boar) of 'poor' sperm quality were diluted in BTS supplemented with $0,1,2,4,8,16$ or $32 \mathrm{mM}$ pentoxifylline and incubated in a water bath for $300 \mathrm{~min}$. Motility and viability data were analysed 30, 150 and 300 min after thawing. This experiment was repeated nine times. Post-thaw samples with both 'good' and 'poor' sperm quality, incubated for 30 and 150 min in BTS and supplemented with $0,2,4,8$ and $16 \mathrm{mM}$, were used to inseminate 1898 in vitro matured oocytes, in four replicates, to assess IVF parameters.

\section{Statistical analyses}

All data processing and statistical analyses were performed in SPSS, version 14.0 (SPSS Inc., Chicago, IL, USA). Data were analysed using an ANOVA with a MIXED procedure. Percentage data (as the square root of the proportion) of postthaw sperm quality parameters were arc-sin transformed before the ANOVA. IVF data (percentage penetrated and monospermic oocyte and efficiency of fertilisation) were modelled according to a binomial model of the parameters, as described by Fisz (1980) before analysis. When the ANOVA revealed 
a significant effect, means were compared using a Bonferroni test and were considered to be significant when $P<0.05$. The ANOVA models included the fixed effects of pentoxifylline concentration (Experiments 1 and 2), the post-thaw incubation time and sperm quality (Experiment 2) and the random effect of the replicate. Results are presented as least-square means \pm S.E.M.

\section{Declaration of interest}

The authors declare that there is no conflict of interest that would prejudice the impartiality of this scientific work.

\section{Funding}

This study was supported by CICYT (AGL2005-00760) and the SENECA foundation of Murcia (04543/GERM/07).

\section{Acknowledgements}

The authors wish to thank Prof. W M C Maxwell for helpful discussions and for his critical reading of the manuscript.

\section{References}

Abeydeera LR \& Day BN 1997 Fertilization and subsequent development in vitro of pig oocytes inseminated in a modified tris-buffered medium with frozen-thawed ejaculated spermatozoa. Biology of Reproduction 57 729-734.

Aitken RJ 1997 Molecular mechanisms regulating sperm function. Molecular Human Reproduction 3 169-173.

Armstrong VL, Clulow J, Murdoch RN \& Jones RC 1994 Intracellular signal transduction mechanisms of rat epididymal spermatozoa and their relationship to motility and metabolism. Molecular Reproduction and Development 38 77-84.

Bathgate R, Maxwell WMC \& Evans G 2006 Studies on the effect of supplementing boar semen cryopreservation media with different avian egg yolk types on in vitro post-thaw sperm quality. Reproduction in Domestic Animals 41 68-73.

Bell M, Wang R, Hellstrom WJG \& Sikka SC 1993 Effect of cryoprotective additives and cryopreservation protocol on sperm membrane lipid peroxidation and recovery of motile spermatozoa. Journal of Andrology 14 472-478.

Breininger E, Beorlegui NB, O'Flaherty CM \& Beconi MT 2005 Alpha-tocopherol improves biochemical and dynamic parameters in cryopreserved boar semen. Theriogenology 63 2126-2135.

Brennan AP \& Holden CA 1995 Pentoxifylline-supplemented cryoprotectant improves human sperm motility after cryopreservation. Human Reproduction 10 2308-2312.

Carvajal G, Cuello C, Ruiz M, Vazquez JM, Martinez EA \& Roca J 2004 Effects of centrifugation before freezing on boar sperm cryosurvival. Journal of Andrology 25 389-396.

Cerolini S, Maldjian A, Pizzi F \& Gliozzi TM 2001 Changes in sperm quality and lipid composition during cryopreservation of boar semen. Reproduction 121 395-401.

Corcuera BD, Marigorta P, Sagües A, Saiz-Cidoncha F \& Perez-Gutierrez JF 2007 Effect of lactose and glycerol on the motility, normal apical ridge, chromatin condensation and chromatin stability of frozen boar spermatozoa. Theriogenology 67 1150-1157.

De Mercado E, Hernandez M, Sanz E, Rodriguez A, Gomez E, Vazquez JM, Martinez EA \& Roca J 2009 Evaluation of L-glutamine for cryopreservation of boar spermatozoa. Animal Reproduction Science 115 149-157.

Eriksson BM, Vazquez JM, Martinez EA, Roca J, Lucas X \& RodríguezMartínez H 2001 Effects of holding time during cooling and of type of package on plasma membrane integrity, motility and in vitro oocyte penetration ability of frozen-thawed boar spermatozoa. Theriogenology 55 1593-1605.

Esteves SC, Sharma RK, Thomas AJ \& Agarwal A 1998 Cryopreservation of human spermatozoa with pentoxifylline improves the post-thaw agonistinduced acrosome reaction rate. Human Reproduction 13 3384-3389.

Fisz M 1980 Some probability distributions. In Probability Theory and Mathematical Statistics, pp 129-174. Ed. R De Krieger. Malabar, FL, USA: John Wiley \& Sons, Inc.

Garbers DL, Lust WD, First NL \& Lardy HA 1971 Effects of phosphodiesterase inhibitors and cyclic nucleotides on sperm respiration and motility. Biochemistry 10 1825-1831.

Gavella M, Lipovac V \& Marotti T 1991 Effect of pentoxifylline on superoxide anion production by human sperm. International Journal of Andrology 14 320-327.

Glogowski J, Danforth DR \& Ciereszko A 2002 Inhibition of alkaline phosphatase activity of boar semen by pentoxifylline, caffeine, and teophylline. Journal of Andrology 23 783-792.

Gradil CM \& Ball BA 2000 The use of pentoxifylline to improve motility of cryopreserved equine spermatozoa. Theriogenology 54 1041-1047.

Grossfeld R, Sieg B, Struckmann C, Frenzel A, Maxwell WM \& Rath D 2008 New aspects of boar semen freezing strategies. Theriogenology $\mathbf{7 0}$ $1225-1233$.

Hammitt DG, Bedia E, Rogers PR, Syrop CH, Donovan JF \& Williamson RA 1989 Comparison of motility stimulants for cryopreserved human semen. Fertility and Sterility $\mathbf{5 2}$ 495-502.

Hu J-H, Li QW, Jiang ZL, Yang H, Zhang SS \& Zhao HW 2009 The cryoprotective effect of trehalose supplementation on boar spermatozoa quality. Reproduction in Domestic Animals 44 571-575.

Huang PT, Chen SU, Chao KH, Chen CD, Ho HN \& Yang YS 2003 Effects of fertilization promoting peptide, adenosine, and pentoxifylline on thawed human sperm. Archives of Andrology 49 145-153.

Johnson LA, Aalbers JG \& Grooten HJG 1988 Artificial insemination of swine: fecundity of boar semen stored in Beltsville TS (BTS), modified modena (MM) or MR-A and inseminated on one, three and four days after collection. Zuchthygyene 23 49-55.

Johnson LA, Weitze KF, Fiser P \& Maxwell WMC 2000 Storage of boar semen. Animal Reproduction Science 62 143-172.

Koutsarova N, Todorov P \& Koutsarov G 1997 Effect of pentoxifylline on motility and longevity of fresh and thawed dog spermatozoa. Journal of Reproduction and Fertility Supplement 51 117-121.

Marques A, Arruda RP, Celeghini ECC, Gobesso AAO \& Neves Neto JR 2002 Effects of ascorbic acid and pentoxifylline on equine cryopreserved semen submitted to in vitro incubation. Theriogenology 58 257-260.

Maxwell WMC \& Johnson LA 1999 Physiology of spermatozoa at high dilution rates: the influence of seminal plasma. Theriogenology $\mathbf{5 2}$ 1353-1362.

Maxwell WMC, Robinson SJ, Roca J, Molinia FC, Sanchez-Partida LG \& Evans G 1995 Motility, acrosome integrity and fertility of frozen ram spermatozoa treated with caffeine, pentoxifylline, CAMP, 2-deoxyadenosine and kallikrein. Reproduction, Fertility, and Development 7 1081-1087.

McKinney KA, Lewis SEM \& Thompson W 1996 The effects of pentoxifylline on the generation of reactive oxygen species and lipid peroxidation in human spermatozoa. Andrologia 28 15-20.

McLaughlin EA, Ford WCL \& Hull MGR 1992 Effect of the phosphodiesterase inhibitor pentoxifylline and the calcium ionophore A23187 on the intracellular CAMP content and the acrosome reaction of human spermatozoa. Journal of Reproduction and Fertility. Abstract Series 1094.

Nassar A, Morshedi M, Mahony M, Srisombut C, Lin MH \& Oehninger S 1999 Pentoxifylline stimulates various sperm motion parameters and cervical mucus penetrability in patients with asthenozoospermia. Andrologia 31 9-15.

Numabe T, Oikawa T, Kikuchi T \& Horiuchi T 2001 Pentoxifylline improves in vitro fertilization and subsequent development of bovine oocytes. Theriogenology $\mathbf{5 6}$ 225-233.

Okada H, Tatsumi N, Kanzaki M, Fujisawa M, Arakawa S \& Kamidono S 1997 Formation of reactive oxygen species by spermatozoa from asthenospermic patients: response to treatment with pentoxifylline. Journal of Urology 157 2140-2146.

Paul M, Sumpter JP \& Lindsay KS 1995 Action of pentoxifylline directly on semen. Human Reproduction 10 354-359. 
Petters RM \& Wells KD 1993 Culture of pig embryos. Journal of Reproduction and Fertility 48 61-73.

Roca J, Gil MA, Hernandez M, Parrilla I, Vázquez JM \& Martinez EA 2004 Survival and fertility of boar spermatozoa after freeze-thawing in extender supplemented with butylated hydroxytoluene. Journal of Andrology 25 5-18.

Roca J, Rodriguez-Martinez H, Vazquez JM, Bolarin A, Hernandez M, Saravia F, Wallgren M \& Martinez EA 2005a Strategies to improve the fertility of frozen-thawed boar semen for artificial insemination. In Control of Pig Reproduction VII, pp 261-276. Eds CJ Ashworth \& RR Kraeling. Nottingham, UK: Nottingam University Press.

Roca J, Rodrguez MJ, Gil MA, Carvajal G, Garcia EM, Cuello C, Vazquez JM \& Martinez EA 2005b Survival and in vitro fertility of boar spermatozoa frozen in the presence of superoxide dismutase and/or catalase. Journal of Andrology 26 15-24.

Stachecki JJ, Dresser BL, Pope CE \& Armant DR 1995 Stimulation of ejaculated domestic cat sperm motility with caffeine, pentoxifylline, and 2'-deoxyadenosine. Archives of Andrology 34 63-68.

Stanic P, Sonicki Z \& Suchanek E 2002 Effect of pentoxifylline on motility and membrane integrity of cryopreserved human spermatozoa. International Journal of Andrology 25 186-190.

Tash JS 1976 Investigations on adenosine 3', 5'-monophosphate phosphodiesterase in ram semen and initical characterization of a sperm-specific isoenzyme. Journal of Reproduction and Fertility 47 63-72.

Tesarik J, Thébault A \& Testart J 1992 Effect of pentoxifylline on sperm movement characteristics in normozoospermic and asthenozoospermic specimens. Human Reproduction 7 1257-1263.

Thurston LM, Watson PF \& Holt WV 1999 Sources of variation in the morphological characteristics of sperm subpopulations assessed objectively by a novel automated sperm morphology analysis system. Journal of Reproduction and Fertility 117 271-280.

Tournaye H, Janssens R, Verheyen G, Devroey P \& Van Steirteghem A 1994 In vitro fertilization in couples with previous fertilization failure using sperm incubated with pentoxifylline and 2-deoxyadenosine. Fertility and Sterility 62 574-579.

Wang R, Sikka SC, Veeragaven K, Bell M \& Hellstrom WJG 1993 Platelet activating factor and pentoxifylline as human sperm cryoprotectant. Fertility and Sterility $60711-715$.

Westendorf P, Richter L \& Treu H 1975 Zur tierfgefrierung von ebersperma: labor und besamungsergebnisse mit dem hlsenberger pailleten verfahren. Deutsche Tierärztliche Wochenschrift 82 261-267.

Yanagimach R 1988 Mammalian fertilization. In The Physiology of Reproduction, pp 135-189. Eds E Knobil \& JD Neil. New York, NY, USA: Raven Press.

Yovich JM, Edirisinghe WR, Cummins JM \& Yovich JL 1990 Influence of pentoxifylline in severe male factor infertility. Fertility and Sterility $\mathbf{5 3}$ 715-722.

Yovich JM, Edirisinghe WR \& Jovich JM 1994 Use of the acrosome reaction to ionophore challenge (ARIC) test in managing patients in an assisted reproduction program: a prospective, double blind, randomized controlled study. Fertility and Sterility 61 902-910.

Received 2 July 2009

First decision 21 August 2009

Revised manuscript received 10 December 2009

Accepted 22 December 2009 